\title{
La acción propagandística a favor del Franquismo durante la Guerra Civil Española: la actuación de Juan Pablo Lojendio en Buenos Aires (1936-1939)
}

\author{
Propagandistic action in favor of Franco regime during the \\ Spanish Civil War : the actions of Juan Pablo Lojendio in Buenos \\ Aires (1936-1939)
}

\author{
Alejandra Noemí Ferreyra* \\ Universidad de Buenos Aires \\ Centro de Estudios Sociales de América Latina \\ Consejo Nacional de Investigaciones Científicas y Técnicas, Argentina \\ alejandranoemif@yahoo.com.ar
}

\section{Resumen}

La fractura político-ideológica que se produjo en España ante el inicio de la Guerra Civil en 1936 se trasladó también al seno de la representación diplomática española en la ciudad de Buenos Aires. Ello generó la dimisión a su cargo de algunos miembros de la carrera diplomática en la embajada hispana y a su vez, la progresiva conformación de una sede diplomática paralela que actuaría bajo las órdenes del Gobierno de Burgos en España. En el presente trabajo nos proponemos seguir con detenimiento el derrotero propagandístico y la actuación diplomática del representante oficioso enviado por el General Francisco Franco a la Argentina, Juan Pablo de Lojendio, prestando especial atención a los vínculos que en su accionar fue generando con destacados miembros de la comunidad hispana en Buenos Aires.

\section{Palabras Claves}

Representación diplomática, Juan Pablo de Lojendio, Buenos Aires, Guerra Civil española, Propaganda

\begin{abstract}
The political- ideological fracture that occurred in Spain before the start of the Civil War in 1936 also went to the heart of the Spanish diplomatic representation in Buenos Aires. This caused the resignation from their position as members of the diplomatic service in the Hispanic embassy and in turn, the gradual formation of a parallel embassy would act under the orders of the Burgo's Government in Spain. In
\end{abstract}


this paper we propose to follow closely the propaganda course and the unofficial diplomatic action of the representative sent by Francisco Franco to Argentina, Juan Pablo de Lojendio, whit special attention to the links that his action was generated with prominent members of the Hispanic community in Buenos Aires.

\section{Keywords}

Diplomatic representation - Juan Pablo de Lojendio - Buenos Aires - Spanish Civil War - Propaganda

\section{Introducción}

Es bien sabido que el conflicto bélico que se inició en España en julio de 1936 impactó profundamente tanto a la numerosa comunidad española residente en la Argentina, ${ }^{1}$ como a la sociedad local. ${ }^{2}$ A los pocos días de conocido el alzamiento militar en contra de la II República, la movilización política y social de distintos sectores nacionales y extranjeros en apoyo a uno y otro bando fue en aumento, al mismo tiempo que proliferaron en los medios de comunicación gráfica todo tipo de informaciones, opiniones y juicios relacionados con lo que acontecía en España. ${ }^{3}$

Del mismo modo, la fractura político-ideológica que se produjo en la península ante el inicio de la contienda se trasladó también al seno de la representación diplomática española en la ciudad de Buenos Aires. Ello generó la dimisión a su cargo de algunos miembros de la carrera diplomática en la embajada hispana, y a su vez, la progresiva conformación de una suerte de embajada paralela que actuaría bajo las órdenes de los sediciosos en España. Este proceso fue reforzado desde la zona bajo control rebelde con el envío de un representante oficioso que arribó a estas costas en diciembre de 1936 e inició una activa campaña de solidaridad y apoyo ideológico a

\footnotetext{
*Este trabajo forma parte de los siguientes Proyectos de Investigación: "Los españoles en Buenos Aires: estrategias de integración socio-cultural y (re)configuraciones identitarias (1914-1960)", UBACyT 20020150100063BA, dirigido por la Dra. Nadia De Cristóforis. Y "Redes, poder y territorialidad en la historia argentina de los siglos XVIII-XX"; Programa de Incentivos a docentesinvestigadores (UNICEN-CESAL), dirigido por la Dra. María Andrea Reguera.

${ }^{1}$ Se calcula que entre un millón y medio y dos millones de españoles vivían en la Argentina (sobre un total de 12 millones de personas de población total). Véase: Raanan Rein. "Otro escenario de lucha: franquistas y antifranquistas en la argentina (1936-1949); en Ignacio Klich y Mario Rapoport (eds). Discriminación y racismo en América Latina. Buenos Aires, Grupo Editor Latinoamericano, 1997; p. 339.

2 Numerosas investigaciones realizadas al respecto nos dan cuenta de la extensa movilización solidaria que se emprendió en nuestro país a favor de uno y otro bando en el contexto de esta guerra, citamos aquí algunos de los trabajos más significativos: Mónica Quijada. Aires de república, aires de cruzada: la Guerra Civil española en la Argentina, Barcelona, Sendai, 1991; Silvina Montenegro. La Guerra Civil española y la política argentina. Tesis Doctoral, Universidad Complutense de Madrid, Madrid, 2002. [Disponible en: http://www.ucm.es/BUCM/tesis/ghi/ucm-t26475.pdf.], consulta: 3/07/2010; Saúl Luis Casas. "El antifascismo y la lucha política en la argentina en el contexto de la Guerra Civil Española (1936-1941)"; en Congreso la Guerra Civil Española 1936-1939. Sociedad Estatal de conmemoraciones culturales, España, 2006. [Disponible en: http://www.secc.es/media/docs/8 1 sl casas.pdf], consulta: 27/05/2010; Víctor Trifone y Gustavo Svarzman. La repercusión de la Guerra Civil española en la Argentina (1936-1939). Buenos Aires, Centro Editor de América Latina, 1993; entre muchos otros.

${ }^{3}$ Para ampliar, véase: Mónica Quijada. Aires de república...; pp. 209-220.
} 
favor del alzamiento, el cual también pretendía irradiarse hacia el resto de América del Sur.

En este trabajo, nos proponemos seguir con detenimiento el derrotero propagandístico y la actuación diplomática oficiosa del representante de Francisco Franco en la Argentina, Juan Pablo de Lojendio, desde su llegada al país en 1936 hasta su regreso a España una vez concluidas sus funciones como Encargado de Negocios en diciembre de 1939, prestando especial atención a los vínculos que en su accionar fue generando con la comunidad hispana local que adhería al levantamiento. ${ }^{4}$

\section{El inicio de la Guerra Civil y la representación diplomática española en Argentina}

El inicio de la Guerra Civil en España situó al personal de las representaciones diplomáticas hispanas en el extranjero en una situación muy delicada. La división que se materializaba en la tierra de origen también tuvo su correlato en los espacios diplomáticos, por lo que pronto se hizo necesaria la implementación de algún sistema de depuración de los funcionarios que fueran desafectos al régimen republicano y no mostraran la lealtad necesaria para continuar ejerciendo sus cargos de representación oficial. El 22 de julio de 1936 el gobierno republicano promulgó un Decreto por el cual dictaminaba el cese inmediato de aquellos empleados estatales que hubiesen participado o simpatizado con el alzamiento. ${ }^{5} \mathrm{Al}$ mismo tiempo, numerosos miembros de la carrera diplomática habían dimitido voluntariamente y ofrecido sus servicios a los rebeldes, pasando a formar parte de la diplomacia paralela que comenzó a actuar de manera oficiosa a su favor. Producto de este traspase de personal, y a solo un mes de iniciada la contienda civil, más de cien personas se habían separado de sus funciones, número que iría acrecentándose con el correr de los meses y la aplicación de los respectivos mecanismos de depuración. ${ }^{6}$

De las Embajadas españolas existentes en América7 ${ }^{7}$ solo las representaciones de Paraguay, Centroamérica y Perú se manifestaron favorables al levantamiento rebelde, ${ }^{8}$ lo que coincidió en algunos casos con la escasa adhesión pro republicana

\footnotetext{
${ }^{4}$ El interés sobre esta cuestión surge en el marco de una preocupación más amplia y que se inscribe en el marco de la realización de una tesis doctoral en Historia en la Universidad de Buenos Aires, la misma tiene como principal objeto de estudio las acciones de colaboración que desplegaron personas e instituciones de origen español a favor del alzamiento militar iniciado en julio de 1936 en contra de la II República en España.

5 Marina Casanova Gómez. "Depuración de funcionarios diplomáticos durante la Guerra Civil", Espacio, Tiempo y Forma. Serie V, Historia Contemporánea; № 1, 1988, p. 363. [Disponible en: revistas.uned.es/index.php/ETFV/article/download/2653/2514], consulta: 20/11/2015.

${ }^{6}$ Ídem, pp. 364-365.

${ }^{7}$ La representación española estaba constituida por 5 Embajadas, 12 Legaciones y 27 Consulados.

${ }^{8}$ Rosa María Pardo Sanz. "Hispanoamérica en la política nacionalista, 1936-1939". Espacio, Tiempo y Forma, Serie V, Historia Contemporánea; 1992, pp. 211-238. [Disponible en: espacio.uned.es/fez/eserv/bibliuned:ETFSerie5.../Documento.pdf], consulta: 15/07/2015.
} 


\section{La acción propagandística a favor del Franquismo...}

de las colectividades hispanas radicadas en dichos países. ${ }^{9}$ En la Embajada instalada en la Argentina la situación fue diferente, ya que la profunda división que se vivía en la península se replicó también en el seno de su representación diplomática. El inicio de la guerra en España sorprendió al Embajador Enrique Diez-Canedo en pleno proceso de adaptación a su nuevo cargo, puesto que había arribado y presentado sus credenciales apenas unas semanas antes en Buenos Aires. ${ }^{10}$ Con las noticias del alzamiento muchos miembros de la Embajada dimitieron a su cargo y la oficina debió actuar con un mínimo de personal disponible a tal punto que el propio hijo del Embajador debió ayudar en las tareas a su padre, según su propio testimonio. ${ }^{11}$ Lo cierto es que el Ministerio de Estado envió una Circular a la Embajada española en Buenos Aires con fecha del 27 de julio de 1936 con el objeto de conocer: "con que funcionarios cuenta incondicionalmente (...) en la representación del extragero (sic)”. ${ }^{12}$ Esto involucraba también a la representación Consular y Vice Consular en la Argentina, por lo tanto, el Cónsul General en Buenos Aires, Manuel Blasco Garzón, debió elaborar una detallada lista de los funcionarios que mantenían su lealtad a la II República y otra de aquellos que habían renunciado a su cargo. Aunque la respuesta no fue del todo positiva, ya que 20 dignatarios habían dimitido prontamente, se aseguraba que la gran mayoría de los dependientes consulares en el interior del país permanecían fieles al gobierno republicano. ${ }^{13}$

Muchos de los desafectos a la Embajada republicana comenzaron a actuar de manera espontánea como representantes oficiosos del movimiento rebelde. Uno de los primeros en manifestar su solidaridad con el alzamiento fue el Agregado Militar, Emilio Fernández Martos, quien rápidamente se contactó con las autoridades sediciosas para enviar dinero a la península. ${ }^{14}$ Otro destacado representante diplomático que procedió del mismo modo fue el Primer Secretario, Francisco de Amat, quien continuaría con iguales funciones pero esta vez bajo las órdenes directas de Juan Pablo de Lojendio, el representante enviado por el General Francisco Franco a la Argentina en diciembre de 1936.

\footnotetext{
9 Fue emblemático el caso de Perú, analizado con mayor detalle en: Ascensión Martínez Riaza. "La lealtad cuestionada. Adscripción política y conflicto de autoridad en la representación española en el Perú, 1933-1939”. Hispania. Revista Española de Historia; № 233, Vol. LXVI, 2006, pp. 671-695. [Disponible

en: www.flacso.andes.edu.ec/internacional publicade/peru/06ascencion martinez.pdf], consulta: 30/06/2015.

${ }^{10}$ Aurora Diez-Canedo. "Enrique Diez-Canedo, Buenos Aires, 1936: selección de cartas recibidas"; en IX Congreso Argentino de Hispanistas, Asociación Argentina de Hispanistas, La Plata, 2010; p. 4 [Disponible: http://ixcah.fahce.unlp.edu.ar], consulta: 30/06/2015.

11 Ibídem.

12 Archivo General de la Administración (Alcalá de Henares), Consulado de España en Buenos Aires, Caja $\mathrm{N}^{\circ}$ 54/06989, Exp. $\mathrm{N}^{\circ} 1805,1936$.

13 Un total de 78 representantes consulares se mantuvieron fieles al gobierno republicano en la provincia de Buenos Aires y el interior del país, lo que incluía a los Consulados y Viceconsulados de Santa Fe, Bahía Blanca, Córdoba, Mendoza y La Plata. Ibídem.

${ }^{14}$ Archivo General Militar de Ávila (Ávila), Cuartel General del Generalísimo-Estado Mayor, Exp. s/n, "Donativos. Escritos relativos a donativos procedentes de Argentina", 21/09/1936.
} 


\section{La llegada de Juan Pablo de Lojendio y su vinculación con la comunidad española pro nacionalista}

El 31 de diciembre de 1936 llegó a Buenos Aires a bordo del trasatlántico Conte Biancamano, Juan Pablo de Lojendio, en calidad de representante oficial de Francisco Franco. ${ }^{15} \mathrm{Su}$ arribo generó muchas expectativas en el seno de aquellos espacios en gran medida comprometidos con el alzamiento contrario a la II República en España. Desde el inicio de la guerra diversas entidades, agrupaciones y personalidades del ámbito hispano habían comenzado a movilizarse a favor del bando rebelde generando una activa campaña de recolección de dinero, víveres, joyas, ropa, etc. para ser enviados a las zonas dominadas por el ejército sedicioso, así como también, se había iniciado una batalla propagandística para dar a conocer los fundamentos del levantamiento y tratar de paliar el predominio republicano en ese campo. ${ }^{16}$ De esta forma, instituciones preexistentes a la guerra, tales como: el Centro Acción Española, la Agrupación Monárquica Tradicionalista y la Agrupación Monárquica Española, a las que se sumaron luego entidades creadas con el objeto de contribuir en el esfuerzo bélico, tales como: los Legionarios Civiles de Franco, la Asociación Acción Gallega Cruzados de Santiago y la Falange Española, fueron conformando el núcleo central de apoyo tanto material como simbólico, que desde Buenos Aires se solidarizaba con el bando nacionalista en la península. ${ }^{17}$

La llegada de Juan Pablo de Lojendio a Buenos Aires fue saludada con entusiasmo en estos ámbitos en donde su sola presencia representaba el reconocimiento del General Franco a la labor que desarrollaban las comunidades de inmigrantes españoles en América del Sur por la causa nacional:

[...] La colectividad española nacionalista, numerosa y selecta por su pensamiento y por su acción ha encontrado méritos ante el jefe de Estado

\footnotetext{
15 El $1^{\circ}$ de octubre de 1936, el General Franco había sido investido en Burgos con la máxima autoridad en la zona rebelde, es decir, como Jefe de Gobierno del Estado. Para ampliar, véase: Hugh Thomas. $L a$ Guerra Civil Española. España, Ed. Grijalbo, 1981; p. 222.

${ }^{16}$ Luis Velasco Martínez. "La emigración española en Latinoamérica ante la Guerra Civil y el fascismo español: el caso argentino". Anuario colombiano de Historia Social y de la Cultura; Vol. 38, № 2, juldic. 2011 ; pp. 39-54.

17 Otras entidades mantuvieron una actitud ambivalente y de menor compromiso visible ante los bandos enfrentados en la guerra, situación que se escudaba detrás de una "neutralidad" aparente que favorecía a los rebeldes, fue el caso del Club Español, la Asociación Patriótica Española, la Sociedad Española de Beneficencia y la Sociedad Española de Socorros Muros. Para ampliar, véase: Mónica Quijada. Aires de república...; pp. 110-111. En otros casos, la guerra generó importantes disputas en el interior de instituciones de envergadura, tales como el Centro Gallego o el Centro Asturiano. Para ampliar, véase: María Silvia Ospital. "El Centro Asturiano de Buenos Aires y la Guerra Civil española”. Trabajos y comunicaciones (2ำépoca), № 26/27, 2000-2001; pp. 123-247; Antonio Fernández García. "Los círculos de emigrantes ante la guerra de España: la colonia gallega en Buenos Aires". Quinto Centenario; № 16, 1990; pp. 121-134; Nadia De Cristóforis. "El Centro Gallego de Buenos Aires ante la España dividida: tensiones y conflictos en una institución señera de la colectividad”; en: ídem (ed.). La inmigración gallega. Su experiencia asociativa en Buenos Aires (1910-1965). Buenos Aires, Imago Mundi, 2014; pp. 19-44.
} 
español, General Franco, y por eso nos envía un personaje de la talla de este nuevo embajador que ya está a nuestro lado. ${ }^{18}$

Aunque la carrera diplomática de J. P. de Lojendio no fuera extensa (había ingresado en 1930) había transitado por diversos puestos y destinos: se había desempeñado como Secretario en la Embajada española de Santiago de Chile y de Marruecos, y como Cónsul en la ciudad de Córdoba y en Niza, lugar en donde se encontraba al momento de iniciarse la Guerra Civil. ${ }^{19}$ A pesar de ser un diplomático de segunda línea, la prensa nacionalista ensalzó sus cualidades personales, expresando una positiva primera impresión del representante:

[...] La importancia del diplomático Sr. Lojendio -aparte de sus dotes intelectuales y de cultura- radica precisamente en una jovialidad exenta de protocolos que inspira respeto, simpatía y confianza al mismo tiempo (...) Nuestro joven y culto diplomático, sin dudas ha de granjearse las simpatías, no solamente de nuestros compatriotas, sino también la de los argentinos, por su poder de captación noblemente inspirada. ${ }^{20}$

En las primeras semanas de su estadía en América del Sur se encontró muy ocupado conociendo y entablando relaciones con aquellos grupos adeptos al alzamiento. En este marco realizó una visita al edificio situado en la calle Bernardo de Irigoyen 483 en el cual tenían su sede los organismos más destacados en la movilización pro nacionalista de Buenos Aires: el Centro Acción Española, la Agrupación Tradicionalista Monárquica, la Asociación Gallega de Cruzados de Santiago y la Falange Española,21 en compañía del ex Secretario de la Embajada española, Francisco de Amat, y de Monseñor Gustavo Franceschi. ${ }^{22}$ En estos primeros momentos, el núcleo español adherente al Movimiento Nacional mantenía una evidente confianza sobre la labor propagandística del enviado del General Franco y en virtud de ello, fue objeto de las más diversas celebraciones y homenajes que requerían su presencia constantemente, llegando incluso a concretarse la realización de un "Plato Único"23 para rendirle tributo (Imagen $\mathrm{N}^{\circ} 1$ ). ${ }^{24}$ Esta fue una

18 "D. Juan Pablo de Lojendio saluda a los nacionalistas españoles y españolistas por intermedio de Acción Española". Acción Española; N 46, Buenos Aires, 1/01/1937; p. 12.

${ }^{19}$ Ibídem.

${ }^{20}$ Félix Rangil, "Breve entrevista con el Embajador del Gobierno de Burgos". Acción Española; Nㅜ 46 Buenos Aires, 1/01/1937; p. 12. También el órgano oficial de Falange Española se manifestó en términos similares: "Llega a Bs. As. El señor Juan Pablo de Lojendio. Enviado especial del gobierno del Gral. Franco". Falange Española; $\mathrm{N}^{\circ} 13$, Buenos Aires, 3/01/1937; p. 4.

21 “Don Juan Pablo de Lojendio visito el Centro Acción Española”. Acción Española; № 48, Buenos Aires, 4/02/1937; p. 3.

22 "La visita del representante del generalísimo Franco a entidades españolas". El Diario Español; Buenos Aires, 17/01/1937; p. 5.

${ }^{23}$ Esta idea había surgido de la Alemania nacionalsocialista e implicaba que se consumía un solo plato pero se pagaba el menú completo, entregándose la recaudación de la diferencia del coste para fines benéficos. Se estableció en España por primera vez el 30 de octubre de 1936. Luis Jerez Riesco. Voluntad de Imperio. La Falange en Argentina. Barcelona, Ediciones Nueva República, 2007; pp. 243244

${ }^{24}$ Por ejemplo, el reconocido periodista católico Félix Ortiz y San Pelayo ofreció un almuerzo en homenaje a J. P. de Lojendio que sirvió como excusa para presentarlo ante sus amistades personales y de esa forma tratar de introducirlo en la elite española y local. Más de cuarenta personas fueron 
de las únicas ocasiones en las que se congregaron la mayoría de las instituciones favorables al alzamiento para apoyar a la causa de manera conjunta. ${ }^{25}$ Este evento fue considerado un verdadero éxito para la "cruzada" nacional, ya que además de una concurrencia por demás satisfactoria, se hallaban presentes el Senador argentino Matías Sánchez Sorondo, un reconocido simpatizante del alzamiento, Felipe García Ontiveros, el ex Embajador español en Paraguay, y los presidentes de todas las instituciones organizadoras. Todos ellos tuvieron el espacio para emitir sus discursos exhortando a la solidaridad para con el movimiento rebelde, los cuales a su vez, fueron retrasmitidos por Radio Cultura. ${ }^{26}$

Además de su asistencia a estos actos proselitistas, el representante del General Franco viajó frecuentemente con fines propagandísticos, sobre todo durante su primer año como agente oficioso, participó de diversos actos y visitó entidades afines, desde Juntas Nacionalistas hasta locales de Falange Española, tanto en el interior del país (Rosario, Mendoza, Jujuy, Tucumán, Córdoba, Santiago del Estero) como en el exterior (Chile y Uruguay). El núcleo nacionalista español veía en él a un auténtico y encendido orador, por ello, en las fechas conmemorativas más importantes su presencia y discursos eran solicitados. ${ }^{27}$

Imagen $\mathrm{N}^{\circ} 1$



invitadas, entre las que se encontraban Rafael Benjumea y Burín, Conde de Guadalhorce, el Dr. Gustavo Martínez de Zuviria (escritor católico conocido por su seudónimo "Hugo Wast") y Rafael Vehils, (abogado e industrial que se desempeñó como presidente de la Cámara Española de Comercio en Buenos Aires desde 1923 hasta 1933), entre otros. "En honor de don Juan Pablo Lojendio fue servido ayer un almuerzo en el Plaza Hotel”. El Diario Español; Buenos Aires, 18/04/1937; p. 4.

25 Félix Rangil Alonso, "El día del plato único en Buenos Aires fue un acto de afirmación Nacionalista". Acción Española; № 50, Buenos Aires, 4/03/1937; pp. 6-7; "El almuerzo de "plato único" ofrecido el domingo al representante del Gral. Franco". Falange Española; № 21, Buenos Aires, 27/02/1937; pp. 6-7; “Homenaje a Don Juan Pablo de Lojendio". Fe Gallega; № 4, Buenos Aires, febrero 1937; p. 3.

26 "El homenaje que ayer se ofreció al representante del general Franco, don Juan Pablo de Lojendio, revistió inusitadas proporciones”. El Diario Español; Buenos Aires, 22/02/1937; p. 2.

27 Estas fechas claves eran: el 2 de mayo, en conmemoración a la revuelta española que en 1808 se desarrollo en contra la ocupación francesa de la península; el 12 de octubre, como expresión clave del vínculo histórico y cultural con América y el 18 de julio, por el aniversario del alzamiento. 


\section{La acción propagandística a favor del Franquismo...}

Fuente: "El homenaje que ayer se ofreció al representante del general Franco, don Juan Pablo de Lojendio, revistió inusitadas proporciones". El Diario Español; Buenos Aires, 22/02/1937; p. 2.

Epígrafe: "La cabecera de la mesa durante un banquete que fue ofrecido al representante del General Franco, don Juan Pablo de Lojendio: Dr. Sánchez Sorondo, senador nacional; don Felipe García Ontiveros, embajador de España en Paraguay; Dr. Oller, delegado Tradicionalista en Buenos Aires; Francisco Quintana, representante de la Falange Española; Dr. Burillo, presidente de Agrupación Monárquica; don Emilio Poblet, representante de Acción Española y otros delegados de entidades españolas en la República."

Sin embargo, sus funciones no se reducían solamente al ejercicio de las relaciones públicas, otra de las grandes cuestiones que debía resolver era dotar de forma y estructura a esa sede diplomática paralela a la Embajada republicana que actuaría para brindar un nexo entre los españoles residentes en la Argentina y los territorios ocupados por los rebeldes en la península. Con tal objeto, J. P. de Lojendio acompañado de su secretario Francisco de Amat, y luego de la llegada al país en marzo de 1937, de José Ignacio Ramos como Encargado de Prensa y Propaganda, pusieron en funcionamiento una oficina que debió erigirse desde la nada. La carencia de recursos económicos provenientes desde España para hacer frente a la tarea propagandística en la Argentina fue aminorada por la colaboración de una "veintena de hombres influyentes de la colectividad, con el Marques de Foronda y el Conde de Guadalhorce a la cabeza",28 que acordaron entregarle una cantidad de dinero mensual y un vehículo para su movilización. La Cámara Española de Comercio de Buenos Aires que se había escindido del Gobierno republicano y reconocido al Gobierno de Burgos, ${ }^{29}$ le brindó un espacio en su edificio para que se instalara la representación oficiosa, aunque luego ésta se trasladaría a la sede del Banco Galicia situado en la calle Cangallo 439 de la Capital Federal. ${ }^{30}$

Una de las primeras disposiciones emanadas por esta embajada paralela fue la expedición de nuevos pasaportes, ya que al desconocer la autoridad del Estado español en todo el territorio ocupado por los rebeldes dichos documentos carecían de validez, por ende, se ordenó la autorización de un visado firmado por el propio J. P. Lojendio en el caso de que alguien pretendiera realizar una viaje a la España nacionalista (Imagen $\mathrm{N}^{\circ} 2$ ). ${ }^{31}$

Imagen $\mathrm{N}^{\circ} 2$

\footnotetext{
${ }^{28}$ José Ignacio Ramos. Biografía de mi entorno. Nostalgias, recuerdos, testimonios. Buenos Aires, Ed. Legasa, 1984; p. 286.

${ }^{29}$ Esta acción motivó la queja de la Embajada republicana y un pedido de intervención al Ministerio de Relaciones Exteriores argentino para que impidiera la concreción de la Junta en la que se planeaba la desvinculación de la Cámara España de Comercio a la II República en España. Desde el Ministerio se respondió que dicha cuestión debía dirimirse exclusivamente en el ámbito privado y en relación directa con el gobierno español. Archivo del Ministerio de Relaciones Exteriores, Comercio Internacional y Culto (Argentina), División Política - España, Exp. 12, Caja № 3835, 1937.

${ }^{30}$ José Ignacio Ramos. Biografía de mi entorno...; p. 289.

31 "Para entrar en la España Nacionalista los documentos deben ser visados por el Representante del General Franco". Acción Española; № 55, Buenos Aires, 20/05/1937; p. 6.
} 


\section{Para entrar en la España Nacionalista los documentos deben ser visados por el representante del general Franco}

La representación del general jefe del Fstado y del gobierno nacional de España, en evitación de perjuicios que involuntariamente pudieran irrogarse, pone en conocimiento público que en el territorio español regido por el gobiernó nacional, así como las colonias espańolas y mona del protectorado español en Marruecos, no tienen validez los documentos públicos procedentes de esta República que no sean expedidos o visados por dieha representación, cuya cancillería está instalada en Cangallo 439, escritorios 203 y siguientes.

Fuente: "Para entrar en la España Nacionalista los documentos deben ser visados por el Representante del General Franco". Acción Española; № 55, Buenos Aires, 20/05/1937; p. 6.

Otra de las cuestiones, tal vez de mayor importancia para los españoles residentes en Buenos Aires, era el tema del envío de correo postal y paquetes para la zona nacional, ya que muchos inmigrantes requerían algún servicio que pudiera llegar a sus familiares y/o amigos en ese territorio. Con tal objeto se estableció el llamado "Paquete Bicolor", el mismo incluía el envío de bultos de 5 y 10 kilos, los cuales, se aseguraba, estaban libres del control de aduanas. ${ }^{32}$ No obstante, este servicio que permitía una mayor fluidez en los envíos con la zona dominada por los rebeldes fue organizado recién en octubre de 1938, previamente, la Representación oficiosa había detallado una lista de aquellas compañías navieras y aéreas que podrían utilizarse para remitir elementos a dicho territorio. Para el envío postal se indicaban como preferentes los vapores de bandera alemana, italiana o inglesa que hicieran escala en Lisboa o en Gibraltar, para el envío aéreo se sugería utilizar la empresa "Cóndor" y para el giro de dinero se certificaba que el Banco de Galicia de Buenos Aires, The First National Bank of Boston y el Banco de la Nación Argentina "con determinadas formalidades", realizaban las operaciones con las mayores seguridades. ${ }^{33}$

Tal como lo advierte María Rosa Prado Sanz, muchos de los miembros del cuerpo diplomático franquista se caracterizaron por mantener una postura de fuerte conservadurismo, en algunos casos cercanos al corporativismo, y un marcado elitismo en función de la tarea que desempeñaban. ${ }^{34}$ Esta parece haber sido la posición del representante de Francisco Franco en la Argentina quien a poco tiempo de su arribo a la ciudad de Buenos Aires calificaba a la mayoría de los inmigrantes españoles allí residentes como:

[...] hombres de acción y de escasa cultura, sin conocer no ya nuestra Historia sino hasta España, un poco agriados porque ven triunfar a algunos de nuestros compatriotas a los que juzgan iguales cuando no

\footnotetext{
32 "Envío de ayuda a familiares en España". Falange Española; № 67, Buenos Aires, 14/01/1938; p. 10; “Encomiendas para la España Nacionalista”. Acción Española; № 78, Buenos Aires, 24/10/1938; p. 3

33 "Representación del Gobierno Nacional de España". Acción Española; № 55, Buenos Aires, 20/05/1937; p. 7.

${ }^{34}$ María Rosa Pardo Sanz. “Hispanoamérica en la política nacionalista...”; pp. 218- 219.
} 
inferiores, resentidos en cierto modo con España porque la necesidad les obligó a emigrar, en un ambiente en que las diferencias de clase social aunque profundas no salen a la superficie como en España, sin otro alimento espiritual que la lectura de periódicos que no hacen más que desorientarles, están entregados por completo a la causa de los marxistas españoles creyéndose muchos de ellos de buena fe que defienden la democracia. Y ¿cómo no va a agradarles la democracia, tal como ellos la entienden, si es de la única forma que pueden lograr una igualdad que nunca podrán conseguir por sus propios méritos? ${ }^{35}$

Estas palabras se adecuaban perfectamente a las instrucciones que le fueron encomendadas para desarrollar sus tareas de captación en el país: “(...) Con relación a la colectividad española, sobre todo la residente en la ciudad de Buenos Aires, la conducta a seguir será la de atraerse a nuestra causa a los que allí han triunfado, es decir a los de calidad y riqueza, pues los demás seguirán a estos en la medida que nuestro Ejército va conquistando territorio, aún en poder de la tiranía roja."36 Esta sería, a grandes rasgos, la línea de acción del Representante de Franco en la Argentina. En los tres años en los que vivió en el país su vinculación con la comunidad española allí residente fue constriñéndose cada vez más, en un primer momento alrededor de los núcleos de mayor poder adquisitivo, y paulatinamente, fue aislándose producto de su enemistad irreconciliable con algunos miembros de Falange Española, y como veremos más adelante, de su escaso tacto para aunar las diversas tendencias político-ideológicas existentes en el seno de los adherentes al alzamiento en la península. ${ }^{37}$

\section{Los intentos de centralizar la ayuda pro nacionalista a la península y las competencias por la autoridad}

Además de su labor propagandística y sus funciones como Representante oficioso, J. P. de Lojendio debía encargarse de articular una tarea aún más compleja: la centralización de las fuerzas afines al bando sublevado en una única organización. Esta disposición emanada directamente desde el Gobierno de Burgos implicaba reunir en un solo espacio a elementos tan dispares como el falangismo y el tradicionalismo carlista, siguiendo la línea de la unificación que se había impuesto a

\footnotetext{
35 Archivo del Ministerio de Asuntos Exteriores (España), J. P. de Lojendio a Duque de Jordana, Leg. R-1003/0, 2/02/1937. Citado en: María Rosa Pardo Sanz, "Hispanoamérica en la política nacionalista...; p. 219. Lamentablemente, no hemos podido acceder personalmente a la documentación que resguarda el citado Archivo ya que desde el año 2010 no se encuentra disponible para la consulta pública por decisión del Estado español.

36 Archivo Ministerio de Asuntos Exteriores (España), "Instrucciones reservadas”, Leg. R-1002/14, 29/09/1938. Citado en: Lorenzo Delgado Gómez- Escalonilla. Imperio de papel. Acción cultural y política exterior durante el primer franquismo. Madrid, CSIC, 1992; p. 121.

37 Ello puede advertirse en el cada vez menor espacio que la prensa nacionalista consultada para el periodo 1936-1939, esto es: Acción Española (órgano oficial del Centro Acción Española), Falange Española (órgano oficial de Falange Española), El Diario Español y Fe Gallega (Órgano oficial de los Cruzados de Santiago Apóstol), le dedican a la cobertura de las acciones de propaganda (discursos, viajes, Platos Únicos, etc.) en las que se hallaba presente J. P. de Lojendio.
} 
ambas facciones en abril de 1937 en la zona nacionalista. ${ }^{38}$ Sin embargo, la presión ejercida no hizo más que ahondar las diferencias entre ellos durante el transcurso de la guerra, y sólo el final de la contienda bélica llegaría a atenuar estas divergencias. ${ }^{39}$

Los esfuerzos de J. P. de Lojendio para incentivar la unión entre el espectro católico/monárquico y el falangismo en la Argentina lo llevaron a dedicarle tiempo a una extensa gira por el país ${ }^{40}$ en la que sus alocuciones se focalizaron en la necesidad de respetar las jerarquías y mantener la obediencia a los mandos superiores. ${ }^{41}$ Como era de esperarse por el rol central que ocupaba la Falange Española en la configuración del Movimiento Nacional luego de la unificación, la constitución del nuevo partido único fue muy bien recibida por sus miembros en la Argentina: “(...) Esperábamos ansiosos este paso constructivo y fortalecedor. La noble rivalidad de falangistas y requetés que se manifestaba en un enorme afán de superación viril y heroica, ha sido motivo de orgullo para todos los españoles (...) pero era también motivo de zozobra y de inquietud para el futuro. (...) la clara visión de nuestro caudillo se anticipó a ello." 42

El Centro Acción Española por su parte, órgano que concentraba la línea de apoyo católica y tradicionalista al alzamiento no fue tan entusiasta en el recibimiento de esta noticia. ${ }^{43}$ Aunque la palabra "unidad" podía generar expectativas positivas, no

\footnotetext{
${ }^{38}$ El 19 de abril de 1937 se publicó el Decreto de Unificación que obligaba a la conformación de un partido único en la España nacionalista, el mismo se nombraba "Falange Española Tradicionalista y de las Juntas de Ofensiva Nacional Sindicalista" y disolvía todas las organizaciones políticas existentes e integraba en su interior a las dos principales fuerzas militares y políticas del movimiento rebelde, la Falange Española y el Tradicionalismo. Para ampliar, véase: Stanley Payne. Falange. Historia del fascismo español. Madrid, Ed. Sarpe, 1985; p. 174.

${ }^{39}$ Lorenzo Delgado Gómez-Escalonilla y Marisa González. "La dinámica franquismo/oposición en Argentina: un ensayo de interpretación (1936-1950)"; en Javier Tusell, Abdón Mateos y Alicia Alted (coords.). La oposición al régimen de Franco. Estado de la cuestión y metodología de la investigación; Tomo I, Vol, 2, Madrid, UNED, 1990; pp. 279-280 y 285; Eduardo González Calleja. "El Servicio Exterior de Falange y la política exterior del primer franquismo: consideraciones previas para su organización". Hispania LIV; Vol. 1, N 186, 1994; p. 297-299.

${ }^{40}$ En el mes de mayo de 1937 J. P. de Lojendio inició una gira por distintos puntos del país: Rosario, Córdoba, Jujuy y Tucumán en compañía del Agregado de Prensa José I. Ramos y del periodista español Francisco Casares.

${ }^{41}$ Así lo expresaba en la ciudad de Córdoba: “(...) cumplir con nuestro deber. Deber de disciplina, la obediencia ciega y hermética a las voces de mando que os van a llegar." "Discurso del Exmo sr Lojendio a la Falange Española de Córdoba". El Diario Español; Buenos Aires, 4/5/1937; p. 2. Sus discursos impresos también hacían hincapié en estos y otros puntos del programa nacionalista: Juan Pablo de Lojendio. Origen y contenido del Movimiento Nacional español en Montevideo (Discurso pronunciado en el Teatro Solís en Montevideo el 17 de octubre de 1937). s/d, 1937; ídem. Un gran discurso de Juan Pablo de Lojendio, (Discurso pronunciado en el acto del 2 de mayo de 1937). Buenos Aires, Ediciones OPYPRE, 1937.

42 "Falangistas y requetés unidos por decreto del caudillo constituyen una agrupación denominada Falange Española Tradicionalista de las Jons". Falange Española; № 29, Buenos Aires, 24/04/1937; p. 6.

43 En junio de 1937, un artículo aparecido en Falange Española sostenía que a pesar de la buena voluntad de Falange, un grupo "más o menos encumbrado" haciendo referencia a miembros del Tradicionalismo y los Requetés en Buenos Aires, no demostraba intenciones de unificarse hasta no recibir órdenes oficiales de su líder Manuel Fal Conde, quien se encontraba confinado en Portugal. "Cómo y por qué se ha fundado en Buenos Aires la Falange Española y Tradicionalista de las Jons". Falange Española; № 37, Buenos Aires, 19/06/1937; p. 16.
} 
olvidaban recordar que se trataba de una unificación urgida por las peripecias de la guerra y cuya base nunca debía dejar de ser la religión católica:

[...] Ha sido el milagro de la palabra unión germinando con generosidad (...) vibraciones de patriotismo integro. Vibraciones que no significan renunciar a las convicciones propias, sino que significan unión en la lucha presente para marchar unidos por los caminos de la gloria (...) Han sido abrazos históricos en la retaguardia de Sudamérica, porque formamos un ejército numeroso donde no deben sentirse discrepancias para amar a España aunque cada cual ostente sus ideas, ya que todas están basadas en los principios de religión que han hecho a España gloriosa y seguirán haciéndola después de esta epopeya que asombra al mundo.44

La intención del Representante oficioso de centralizar la ayuda que se enviaba al bando nacional en la península en un solo canal de recaudaciones bajo su estricto control, se concretó recién en junio de 1937 con la organización de la "Suscripción Nacionalista Española".45 A partir de ese momento todas aquellas colectas que invocaran el nombre del Movimiento Nacional o el Ejército de España debían estar previamente autorizadas por la Representación oficiosa del General Franco, de lo contrario, serían consideradas ilícitas. ${ }^{46}$

En buena medida, la superposición de potestades y funciones que caracterizaron al ordenamiento del Gobierno rebelde en el contexto de la guerra ayudó a la creación de situaciones de confusión y competencias por la autoridad. ${ }^{47}$ En este sentido, resulta ejemplar el enfrentamiento que se dio entre J. P. de Lojendio y Nicolás Quintana, Jefe Territorial de la Falange Española en Argentina desde su fundación en julio de $1936^{48}$ hasta su posterior desplazamiento, producto de estas desavenencias, en septiembre de 1937.49 Tras la unificación, la reorganización del Servicio Exterior de Falange Española tendría un importante efecto sobre la canalización de la propaganda del régimen hacia América Latina, ${ }^{50}$ y por ello mismo, se generaron situaciones de duplicación de competencias entre los miembros de la

\footnotetext{
44 “Una unión sellada con abrazos”. Acción Española; № 55, Buenos Aires, 20/05/1937; p. 1.

45 Esta suscripción se encontraba bajo la supervisión de un comité de control, compuesto por: Francisco de Amat en calidad de presidente; el Agregado de Prensa y Propaganda, José Ignacio Ramos y como secretarios: Juan Manuel Muñoz y Luis Marquina. “Comunicado de la representación del Estado Español”. Acción Española; № 57, Buenos Aires, 18/06/1937; p. 3.

${ }^{46}$ En septiembre de 1937, las únicas entidades autorizadas para continuar con las suscripciones eran: Legionarios Civiles de Franco, Socorro Blanco Argentino para la Reconstrucción de España y SALVE (Socorro Argentino a las víctimas de la guerra en España). Orientación Española. Oficina de propaganda y prensa de la representación del Gobierno Nacional de España; Año I, № 1, Buenos Aires, 1937; p. 21.

47 María Rosa Pardo Sanz. "Hispanoamérica en la política nacionalista..."; p. 222.

48 La Falange Española en Buenos Aires se constituyó oficialmente el 1 de agosto de 1936, pero la idea surgió a partir de la iniciativa de una serie de hombres conmovidos y movilizados ante las noticias del asesinato del diputado de la derecha española José Calvo Sotelo el 14 de julio de 1936. Para ampliar, véase: José Luis Riesco. Voluntad de Imperio...; pp. 66-67.

${ }^{49}$ Lorenzo Delgado Gómez- Escalonilla. Imperio de papel...; p. 136.

${ }^{50}$ Esta sección, creada en febrero de 1937, alcanzó el rango de Delegación Nacional de FET y fue encomendada para vincularse e incorporar al nuevo Estado a los españoles residentes en el extranjero. Para ampliar: Eduardo González Calleja. "El Servicio Exterior de Falange y la política exterior..."; p. 297.
} 
Falange y los representantes oficiosos del Gobierno de Burgos. ${ }^{51}$ Aunque se esperaba que las relaciones entre los agentes diplomáticos del movimiento rebelde y las organizaciones de la Falange fuera de cooperación mutua con el objeto de atraerse a la opinión pública a la causa, sabemos que en la Argentina no se logró ese entendimiento.

Como vimos anteriormente, cuando el Representante del General Franco llegó al país se encargó personalmente de entablar vínculos con todas las organizaciones afines al alzamiento. La Falange Española no fue la excepción, y por esa razón durante sus primeras semanas en el Rio de la Plata, J. P. de Lojendio recibió a una comisión falangista en su residencia en donde les brindó una cordial entrevista en la que recordó su cercanía con la agrupación:

\begin{abstract}
[...] tiene con la Falange y sus fundadores vínculos antiguos y de buena amistad. Al comenzar la guerra, de Lojendio al presentarse a las autoridades de Pamplona como teniente de Artillería fue designado por el comando militar para mandar a los falangistas de Estella que fueron los primeros voluntarios que se presentaron a militarizarse. Soy - nos dice el Sr. Lojendio -, un soldado de la primera hora y de la primera fila. Traigo por lo tanto, y quiero no perderlo, el espíritu de esa vanguardia generosa y heroica que lleva cinco meses combatiendo por Dios y por España. (...) Ya lo verán ustedes nuestras colectividades en América serán un buen barómetro de nuestra labor. ${ }^{52}$
\end{abstract}

El Jefe Territorial de Falange Española en la Argentina, Nicolás Quintana, acompañó a J. P. de Lojendio en los primeros eventos que lo tuvieron como protagonista, pero con el correr de los meses se fueron distanciando. La rivalidad entre el agente oficioso y la cúpula de la Falange Española se hizo evidente ante la llegada de la denominada "Misión de la Bandera de Marruecos" en América, compuesta por Juan Antonio Martin Cotano, Joaquín Arbeloya, Rafael Duyos y Antonio Solano Ruiz, en julio de 1937..$^{53}$ Esta fue la primera "Misión Cultural" con fines propagandísticos y de supervisión enviada por el General Franco al Cono Sur, en colaboración con el Alto Comisariado de Marruecos.

Al llegar a Buenos Aires, para su sorpresa y pesar, se encontraron con una colectividad dividida, al intentar entrevistarse con J. P. de Lojendio, acompañados por su Jefe Nicolás Quintana, el primero se negó rotundamente a recibirlos. El poeta Rafael Duyos se encargó de describirle en detalle en una carta confidencial al Jefe de Prensa y Propaganda de Falange Española en Tetuán, José Aragón Caziñares, todas las peripecias que debieron sortear los miembros de esta "Misión” en Buenos Aires para poder llevar adelante sus propósitos. ${ }^{54}$ En esta extensa misiva, Duyos

\footnotetext{
51 Lorenzo Delgado Gómez- Escalonilla. Imperio de papel...; pp. 137-139.

52 "Llega a Bs. As. El señor Juan Pablo de Lojendio. Enviado especial del gobierno del Gral. Franco". Falange Española; № 13, Buenos Aires, 13/01/1937; p. 4.

53 “Bienvenidos". Falange Española; № 40, Buenos Aires, 9/07/1937; p. 2.

${ }^{54}$ Esta carta de carácter confidencial fue enviada "con toda urgencia y discreción" a Tetuán, pero fue interceptada en Sevilla y redirigida al Cuartel General con el objeto de analizar las conflictivas relaciones que allí se expresaban entre Falange y la Representación oficiosa en Argentina. Archivo
} 
puntualizó las muestras claras de una fuerte interna por la autoridad en el núcleo afín al bando nacionalista porteño y un desconocimiento total a las directivas de la unificación impuestas por el General Franco:

\begin{abstract}
[...] Uno a esto una verdadera anarquía entre los 500.000 españoles radicados en Buenos Aires, divididos en: 350.000 rojos exaltados, moviéndose en un ambiente muy favorable puesto que tienen su gobierno todavía reconocido, mucho dinero, una gran propaganda, gran numero de diarios afectos y un medio absolutamente democrático y parlamentarista.- los otros 150.000 se dividen en: españoles degenerados que perdieron todo su amor a la patria y adquirieron cualquier otra nacionalidad, diciendo a pulmón lleno que nada deben a España, que salieron buscando una vida mejor; en españoles agrupados bajo una bandera monárquica; en españoles agrupados bajo el guión del tradicionalismo; españoles agrupados en una organización que se llama "Legionarios Civiles de Franco"; españoles encuadrados en otra que se llama "Cruzada rojo y gualda", y por último españoles que están al lado del Embajador de España. Todos ellos fuera del decreto de fusión que no piensan cumplir ni les interesa. Todos ellos por consiguiente fuera de Falanges Española Tradicionalista y de las Jons, único órgano entre el Estado y el pueblo con su doctrina convertida en norma programática del nuevo estado.- (...) permitiendo la falta de espíritu de auténtica orientación que se desconozca toda la esencia del Movimiento - ya ves se piensa aquí que luchamos por una restauración monárquica- $(\ldots)^{55}$
\end{abstract}

Este panorama de desorganización que dibujó Duyos no pasó desapercibido para las autoridades rebeldes, ${ }^{56}$ ya que en octubre de 1937 se nombró a Augusto Atalaya como "Inspector General de Falange Española" en América, con jurisdicción en Argentina, Uruguay, Chile y Paraguay. ${ }^{57}$ El resultado de esta designación fue el casi inmediato desplazamiento de Nicolás Quintana de la Jefatura Territorial de Falange, la cual paso luego a manos de Juan A. Martin Cotano, quien fuera miembro de la "Misión" cultural venida de Marruecos. ${ }^{58}$

De esta manera, la sección Argentina de Falange Española se encontró intervenida directamente por las autoridades peninsulares con el objeto de evitar el recrudecimiento de los conflictos internos. No obstante, el encono de J. P. Lojendio con la Falange Española en Buenos Aires no terminó con la destitución de N.

General Militar de Ávila (Ávila), Cuartel General del Generalísimo-Estado Mayor, Exp. s/n, "Notas informativas de relaciones con la Falange Argentina", 20/08/1937.

55 Ídem, fols. 4-5.

56 El mismo solicitaba la urgente intervención de las autoridades de la península para resolver estas disputas: “(...) He dado los oportunos avisos a Salamanca para que envíen un Inspector que normalice estas cosas, destituya, rectifique, nombre o ratifique en los cargos. Que sea falangista, muy falangista y con facultades plenas del Secretariado Político y del Generalísimo. Aquí hacen falta hombres de verdadera talla y de acción. Que sepan aprovechar lo que por fortuna está latente en el corazón de los criollos, pues NO DEBE OLVIDARSE QUE ESTOS SON LOS QUE MEJOR AYUDAN AHORA, NOS AYUDARAN LUEGO Y ARRASTRARAN CONSIGO A MUCHOS MILES DE ESPAÑOLES." ídem, fol. 5. Mayúsculas en el original.

57 Atalaya había llegado a la Argentina en agosto de ese mismo año en calidad de Jefe de la "Misión de la Bandera de Marruecos". "Llegada a Buenos Aires del jefe de Falange en Marruecos". Falange Española; № 44, Buenos Aires, 7/08/1937; p. 3.

58 “Falange Española Tradicionalista”. Falange Española; № 49, Buenos Aires, 11/09/1937; p. 8. 
Quintana, ya que meses después continuaban los conflictos alrededor de los escasos capitales de los que se disponían para hacer frente a los gastos de propaganda. ${ }^{59}$ Puntualmente, desde el falangismo se cuestionaba la aparición de nuevas publicaciones tales como Orientación Española y La Ametralladora (septiembre de 1937), mientras que el semanario de Falange Española languidecía por la falta de recursos y de anunciantes, debido a que muchos de ellos retiraban su suscripción para pasarlas a esos nuevos emprendimientos que contaban con el aval del Agregado de Prensa y Propaganda y del Representante oficioso del Gobierno de Burgos:

[...] las conocidas tendencias poco falangistas del agente oficioso del
Estado, Sr. Lojendio, hace que los medios acomodados del país estén en
pugna con la obra de Falange, lo que en terreno práctico se convierte para
nuestro periódico en una escasez de anuncios muy en contraste con la
liberalidad que los otorgan a las publicaciones de propaganda del Estado.
Lo que se está haciendo en la Argentina es simplemente el desorientar a
la opinión de los españoles residentes en aquel país y de los simpatizantes
argentinos haciéndoles creer que dentro del Movimiento Nacional existe
una rivalidad". ${ }^{60}$

Podría decirse que en esta disputa de poder, finalmente J. P. de Lojendio fue quien salió victorioso ya que logró continuar en su cargo por dos años más, teniendo además el privilegio de ser reconocido por del Estado argentino como Encargado de Negocios de España y de ocupar el edificio de la Embajada española en Buenos Aires luego de la finalización de la Guerra Civil.61

No obstante sus éxitos en el plano formal, a nivel interpersonal no logró crear un vínculo estable con la comunidad española nacionalista residente en la ciudad. A pesar de sus esfuerzos por concretar la unidad entre los adherentes al bando nacional, no consiguió resolver satisfactoriamente las discrepancias con el sector falangista y su excesivo elitismo lo terminó alejando de cualquier posibilidad de atraer una mayor popularidad al bando que finalmente terminaría ganado la guerra. En una entrevista concedida al Correo de Galicia los primeros días de enero de 1939, cuando la situación bélica ya se encontraba visiblemente a favor de los rebeldes, J. P. de Lojendio declaraba: “(...) ¿La mayoría? La mayoría es indiferente, amorfa, frívola. (...) Porque la única función de la mayoría- en cualquier régimen con o sin elecciones- no es otra que ser instrumento en manos de una minoría, llámese Jefe o Comité."62

Una visión despectiva sobre una comunidad española mayoritariamente popular y cercana al republicanismo, lo llevó a desestimar cualquier programa

\footnotetext{
59 Archivo General de la Administración (Alcalá de Henares), Delegación Nacional del Servicio Exterior de FET-JONS, Exp., s/n: "Situación de rivalidad de la propaganda del Estado y de la Falange en la Argentina", 22/12/1937, Caja № 51/20923.

${ }^{60}$ Ibídem.

${ }^{61}$ Memoria del Ministerio de Relaciones Exteriores de la República Argentina. Presentada al Honorable Congreso Nacional, período 1938-1939, Tomo I; pp. 179-184.

62 "Palabras del representante del Gobierno Nacional en la República Argentina". Correo de Galicia; Buenos Aires, 1/01/1939; p. 1.
} 
propagandístico que intentara acercarse a ella. Esta postura generó fuertes críticas por parte director del semanario gallego Correo de Galicia, quien a pesar de ser un profundo admirador y adepto a la causa nacional, no aprobó en ningún momento la labor diplomática de J. P. de Lojendio:

[...] Los escasos vehículos de propaganda con que contábamos debieron ser concentrados en un solo esfuerzo (...) En lugar de ese sano procedimiento, una equivocada interpretación de la realidad hizo que se procediese en forma completamente opuesta, estableciendo escisiones $y$ competencias francamente deplorables. (...) Aquí, y el señor Lojendio lo sabe perfectamente, no se ha conseguido infiltrar en la opinión de las gentes nacionalistas esas saludables enseñanzas. No se ha predicado con el ejemplo, porque nuestros actos públicos han quedado reducidos a un mal oculto pugilato de vanidosas exhibiciones y banquetes suntuosos con sus correspondientes y ampulosos discursos de sobremesa, para solaz y recreo de todos los amantes de estas expansiones gastronómicas y teatrales. Así se ha ido alejando el núcleo nacionalista de españoles emigrados en este país, la masa popular que le prestaba el calor de sus nobles y ardientes entusiasmos. (...) Nos ha faltado una dirección y un guía capaz de imponerse a las influencias de los cenáculos y camarillas. (...). Y dicho esto, solo resta desear para el señor Lojendio las más grandes aventuras personales. Por conocer muchas cosas no sería posible culparle más que de un defecto ¡quien no los tiene! El defecto que señalamos es el de mirar demasiado hacia arriba. Abajo está, precisamente, el problema latente de nuestro tiempo. Desconocerlo es vivir dando la espalda a una de las más grandes realidades contemporáneas. ${ }^{63}$

Como José R. Lence, muchos españoles adherentes al alzamiento también pudieron sentirse ignorados por quien había sido enviado especialmente por el General Franco para representarlo durante los años que duró la contienda bélica. Por ello, la partida de J. P. de Lojendio favoreció la distención de los conflictos dentro de la comunidad española afín al bando rebelde, y con la guerra finalizada, las disputas internas fueron suavizándose en el afán de contribuir en conjunto a la reconstrucción de España bajo los parámetros del "Nuevo Estado" franquista.

\section{Conclusiones}

La llegada de J. P. de Lojendio a la Argentina en diciembre de 1936 generó expectativas positivas en aquellos núcleos de la colonia española que se manifestaban favorables al alzamiento militar iniciado en contra de la II República española en julio de 1936. En su carácter de Representante oficioso del General Francisco Franco, Lojendio se encargó de entablar vínculos con todas las principales personalidades y entidades hispanas que simpatizaban con los rebeldes. A su vez, su labor propagandística lo llevó a emprender una gira por el interior del país, visitando distintas provincias, así como también, países limítrofes (Chile y Uruguay). Al mismo tiempo, se encargó de dar forma y estructura a una sede diplomática paralela a la de la Embajada republicana en Buenos Aires, que cumplió con la función

${ }^{63}$ José R. Lence, "Al margen de la partida de Don Juan Pablo de Lojendio". Correo de Galicia; Buenos Aires, 12/11/1939; p. 1. La cursiva es nuestra. 
de visar los pasaportes de quienes pretendieran viajar a la España nacionalista (desconociendo la validez de los pasaportes republicanos) y de gestionar medios de transporte y comunicación entre los españoles residentes en la Argentina y la zona ocupada por los rebeldes en España. Todo ello, gracias al apoyo económico de un grupo de inmigrantes españoles acomodados que se encargó de entregarle al Representante una suma de dinero mensual y un automóvil para que pudiera cumplir con sus funciones.

En líneas generales, podría decirse que si bien el trabajo propagandístico de Lojendio fue constante, la confianza inicial que depositaron en su labor los simpatizantes de la causa nacional al momento de su llegada, no dio los resultados esperados. No sólo no logró organizar una comunidad española nacionalista unificada para hacer frente a la mayor cantidad de recursos y de adherentes con los que contaban los republicanos en el país, sino que, al contrario, las actitudes del Representante oficioso en mucho contribuyeron a la división y la dispersión de energías dentro del núcleo de los adeptos al alzamiento. En pocas palabras, en los tres años que Juan Pablo de Lojendio vivió en la Argentina, no logró generar un vinculo estable con la comunidad española pro nacionalista residente en Buenos Aires, por un lado, debido a sus discrepancias irreconciliables con el falangismo, que se tradujeron en una competencia sin cuartel por la autoridad, lo que concluyó a su vez, en la intervención de la Falange Española local con enviados especiales desde la península. Y por otro lado, por el excesivo elitismo del que hacía gala el Representante oficioso, que lo llevó a distanciarse de los sectores menos encumbrados de la colonia hispana local, así como también, la desunión existente entre los elementos católicos, monárquicos y falangistas, pusieron en evidencia su falta de tacto para propiciar la fusión de fuerzas a la que se pretendía llegar siguiendo las directivas de la unificación impuesta desde el Gobierno de Burgos. Por estas razones, la partida de Lojendio en diciembre de 1939 suavizó los ánimos en el núcleo nacionalista español de Buenos Aires y permitió un mayor acercamiento entre los grupos afines al "Nuevo Estado" franquista, pero esta vez, en el contexto de la reconstrucción post bélica.

\section{Bibliografía}

Casanova Gómez Marina. "Depuración de funcionarios diplomáticos durante la Guerra Civil”, Espacio, Tiempo y Forma. Serie V, Historia Contemporánea; № 1, 1988, p. $363 . \quad$ [Disponible en: revistas.uned.es/index.php/ETFV/article/download/2653/2514]

Casas Saúl Luis. "El antifascismo y la lucha política en la argentina en el contexto de la Guerra Civil Española (1936-1941)"; en Congreso la Guerra Civil Española 19361939. Sociedad Estatal de conmemoraciones culturales, España, 2006. [Disponible en: http://www.secc.es/media/docs/8_1_sl_casas.pdf]

De Cristóforis Nadia. "El Centro Gallego de Buenos Aires ante la España dividida: tensiones y conflictos en una institución señera de la colectividad"; en: ídem (ed.). La inmigración gallega. Su experiencia asociativa en Buenos Aires (1910-1965). Buenos Aires, Imago Mundi, 2014; pp. 19-44. 


\section{La acción propagandística a favor del Franquismo...}

Diez-Canedo Aurora. "Enrique Diez-Canedo, Buenos Aires, 1936: selección de cartas recibidas"; en IX Congreso Argentino de Hispanistas, Asociación Argentina de Hispanistas, La Plata, 2010; p. 4 [Disponible: http://ixcah.fahce.unlp.edu.ar] Fernández García Antonio. "Los círculos de emigrantes ante la guerra de España: la colonia gallega en Buenos Aires”. Quinto Centenario; № 16, 1990; pp. 121-134 Jerez Riesco Luis. Voluntad de Imperio. La Falange en Argentina. Barcelona, Ediciones Nueva República, 2007; pp. 243-244

Martínez Riaza Ascensión. "La lealtad cuestionada. Adscripción política y conflicto de autoridad en la representación española en el Perú, 1933-1939".Hispania. Revista Española de Historia; № 233, Vol. LXVI, 2006, pp. 671-695.[Disponible en: www.flacso.andes.edu.ec/internacional_publicade/peru/06ascencion_martinez.p] Ospital María Silvia. "El Centro Asturiano de Buenos Aires y la Guerra Civil española”. Trabajos y comunicaciones (2o época), № 26/27, 2000-2001.

Pardo Sanz Rosa María. "Hispanoamérica en la política nacionalista, 1936-1939". Espacio, Tiempo y Forma, Serie V, Historia Contemporánea; 1992, pp. 211-238. [Disponible en: e-pacio.uned.es/fez/eserv/bibliuned:ETFSerie5.../Documento.pdf] Quijada Mónica. Aires de república, aires de cruzada: la Guerra Civil española en la Argentina, Barcelona, Sendai, 1991; Silvina Montenegro. La Guerra Civil española y la política argentina. Tesis Doctoral, Universidad Complutense de Madrid, Madrid, 2002. [Disponible en: http://www.ucm.es/BUCM/tesis/ghi/ucm-t26475.pdf.]

Ramos José Ignacio. Biografía de mi entorno. Nostalgias, recuerdos, testimonios. Buenos Aires, Ed. Legasa, 1984.

Rein Raanan. "Otro escenario de lucha: franquistas y antifranquistas en la argentina (1936-1949); en Ignacio Klich y Mario Rapoport (eds). Discriminación y racismo en América Latina. Buenos Aires, Grupo Editor Latinoamericano, 1997.

Thomas Hugh. La Guerra Civil Española. España, Ed. Grijalbo, 1981.

Trifone Víctor y Svarzman Gustavo. La repercusión de la Guerra Civil española en la Argentina (1936-1939). Buenos Aires, Centro Editor de América Latina, 1993.

Velasco Martínez Luis. "La emigración española en Latinoamérica ante la Guerra Civil y el fascismo español: el caso argentino". Anuario colombiano de Historia Social y de la Cultura; Vol. 38, № 2, jul-dic. 2011; pp. 39-54.

\section{Archivos}

Archivo General de la Administración (Alcalá de Henares), Consulado de España en Buenos Aires.

Archivo General Militar de Ávila (Ávila), Cuartel General del Generalísimo-Estado Mayor.

Archivo del Ministerio de Relaciones Exteriores, Comercio Internacional y Culto (Argentina).

\section{Periódicos}

Acción Española

Falange Española

Correo de Galicia

El Diario Español

Fe Gallega

Recibido: 03/02/2016

Evaluado: $25 / 03 / 2016$

Versión Final: 08/04/2016 